\title{
262 MARKETING IN SPORTS: A TOOL FOR DEVELOPING SPORTS
}

Indranil Ghosh Assistant Project Officer (Sports), Organising Committee Commonwealth Games (2010), New Delhi, India

\subsection{6/bjsm.2010.078725.262}

Marketing is the process by which companies create customer interest in products or services. It generates the strategy that underlies sales techniques, business communication and business development It is an integrated process through which companies build strong customer relationships and create value for their customers and for themselves. In sports such marketing strategies are effective tools, which give a company the opportunity to leverage on the passion that consumers have for sports. The reach of sporting organisations into community makes them an ideal vehicle through which they promote health and fitness to general population. There are various agencies which are promoting sports through marketing and sponsorships like Ministry of Youth Affairs \& Sports, International Sports Federations, National Sports Organisations, National Institute of Sports, etc. Such agencies play different role in enhancing sports performance through sponsoring the players, equipments, clubs, etc. For example 
(A) providing platform to budding sports person to build up their career. (B) Duly take care of the market equipment in the field of sports. (C) Fabrication of marketing mix involved organising of an event. (D) Governments aid for sports promotion should be equalised. Here the role of the government is also very important which is to create the infrastructure and promote capacity building for broad-basing sports as well as for achieving excellence in various competitive events at the national and international levels. The Ministry's schemes are geared towards achieving these objectives. So we can conclude that government along with the sports marketing field can provide ample amount of opportunity to the sports organisations as well as to the sports agencies for developing, boosting and re-energising the sports arena. 